\section{Problems for foreigners in Japan}

SIR - Japan is attracting more foreign researchers, although the total number of foreigners is still dwarfed by their Japanese counterparts studying or working overseas (see Nature 350, 4; 1991). Monbusho (Ministry of Education) opened the doors of national universities to foreign lecturers in the 1970 s after a special law was passed by the Diet, and a more significant law in the early 1980 s allowed national universities to employ foreign professors and assistant professors on a permanent basis. In 1986, another progressive amendment allowed foreigners to be employed by the 84 national laboratories. And an increasing number of young foreign researchers are applying for the 200 or so postdoctoral positions in national institutes, in addition to fellowships available within the university system.

Despite these impressive relative gains by ministries with research agencies, Homusho (the Ministry of Justice) is actually moving in the opposite direction, with a more restrictive immigration policy. In July 1990, the law governing the granting of visas was modified, with foreign workers in Japan (in all fields, including research) being eligible for a maximum one-year work permit, in contrast to previous regulations which allowed up to a three-year work permit. Exceptions include medical doctors and lawyers, as well as employees of Monbusho (university lecturers), who may receive up to three-year work permits. At the same time, there is no consistent policy in granting permanent residency. Regardless of apparent regulations, applications are accepted only after a lengthy period on a work permit.

Although a Japanese national institute may offer a foreign researcher a threeyear to lifetime contract, this security is eroded when Homusho offers only single-year visas. This negates all the other efforts being made to integrate foreign workers into the Japanese system, and serves only to encourage foreign researchers to stay home or seek employment elsewhere.

My situation illustrates the inconsistencies a foreigner is faced with. In 1982 I received permanent residency in New Zealand when I joined a Department of Science and Industrial Research (DSIR) national laboratory. This was standard practice, with more than 10 per cent of my DSIR colleagues having been born in Asia, Europe, North America and elsewhere. In April 1989, I moved to Japan to take up a three-year appointment in a national institute of the Agency of Industrial Science and Technology (AIST) of the Ministry of International Trade and Industry (MITI). In my first three years, I was very satisfied with the progress of my research, as well as my working conditions, colleagues and life in Japan. When my contract came up for renewal I was keen to continue, but I requested that there be no expiration date on my new jirei (letter of appointment), the same as that received by all granted and I became the first foreigner in Japan's national institutes to hold a jirei without an expiration date, thus truly joining the permanent staff.

At the expiration of my initial threeyear visa, I requested from the Immigration Bureau another three-year permit and also inquired about permanent residency. Despite my permanent status with a national institute, I was told I could receive only a one-year visa and that I could not yet apply for permanent residency; I might have to wait perhaps a further nine years. The permanent residency aside, I pointed out that Monbusho employees qualify for a three-year visa, often with contracts for specific periods in contrast to my permanent position. The officer agreed that this seemed inequitable, but nevertheless was the law.

In a recent interview by Akwi Seo with Immigration Bureau staff of Homusho (Look Japan 37, 32; December 1991), this apparent inequality between staff of national universities and national institutes was explained: “. . . professorships are difficult to obtain, entail a high degree of social status, and aren't accessible to "just anybody", implying that both Japanese and foreign national institute staff are of lower status. Seo also interviewed a civil-rights lawyer for foreign residents, who said that the agencies that hired foreigners "have failed to exert pressure on the Ministry of Justice, leaving their foreign employees at the mercy of the immigration services", which "prefer issuing short-term visas because they require frequent visits to the Immigration Bureau, helping the Ministry [of Justice] keep track of Japan's growing foreign population". Although some agencies may be slow to advocate the position of their foreign employees to Homusho, AIST has been supportive in my case, but to no avail. The present situation simply reflects the highly conservative nature of Homusho, and the fact that a ministry can and often does ignore requests originating from other ministries.

The case of foreign researchers is only a small part of the much wider issue of foreign labour in Japan. With relatively little experience in dealing with foreigners living and working side by side with Japanese, Japan may benefit from my Japanese colleagues. This was outside views in dealing fairly and consistently with its growing foreign population. Bureaucrats of such a homogeneous society must realize that they can never fully appreciate what it is like to be a gaijin (outsider) in Japan, and the problems we face daily in trying to live and work here, a country many of us choose to call our home. We simply ask for equitable consideration, in a world perspective.

\section{Jeffrey W. Hedenquist}

Geological Survey of Japan,

Tsukuba, Japan

\section{Nineties' research}

SIR - At a recent meeting of the Departmental Nomenclature Committee (DNC), it was agreed to adopt the following minimum set of standards:

(1) All academic members of staff are to be named professor. Individuals should think of suitable titles for themselves, and colleagues should be discouraged from the habit of addressing each other by first names. All other staff should be called research associates, with subtle variations (research associate-in-chief, assistant associate).

(2) All rooms are to be renamed research units: the instrument room is to be called the photonic detection research unit, the dark room the luminosity minimized quantal imaging unit and so on. It is essential that visitors (potential patrons, donors and the rest) should see only the label on the door.

(3) Research groups are to be renamed molecular research groups. The term genetic should be dropped from group titles as market research shows that this word conjures up pictures of bespectacled old men pottering among pea plants obtaining questionable results, a corporate image hardly likely to attract external funds.

These changes should bring the department into line with the other members of the European Communities (making applications for grants more likely to be successful), should impress the public at large, boost our morale and help us to develop a credible corporate profile.

\section{Simon Wolff}

Professor of Molecular

Biohazard Evaluation,

Molecular Environmental

Bioepidemiology Research Unit,

Suite 3.20-3.21,

Third Plaza (Mezzanine),

Division of Molecular Pharmacology

and Molecular Toxicology,

Department of Molecular Medicine,

Molecular Life Sciences Consortium, University College London,

5 University Street,

London WC1E 6J, UK 